\title{
Phase-Equilibrium Studies of the High-Lime Portion of the Quinary System $\mathrm{Na}_{2} \mathrm{O}-\mathrm{CaO}-\mathrm{Al}_{2} \mathrm{O}_{3}-\mathrm{Fe}_{2} \mathrm{O}_{3}-\mathrm{SiO}_{2}{ }^{1}$

\author{
By William R. Eubank ${ }^{2}$
}

\begin{abstract}
Two means, one graphic and the other analytic, for studying the phase-equilibrium. relations in a portion of the five-component system $\mathrm{Na}_{2} \mathrm{O}-\mathrm{CaO}-\mathrm{Al}_{2} \mathrm{O}_{3}-\mathrm{Fe}_{2} \mathrm{O}_{3}-\mathrm{SiO}_{2}$ are described. Using the graphic procedure, compositions in two series of planes in the quinary system were investigated by the quenching method. In each of the two series one component was held constant and another given different values in successive planes. In each plane two components remained constant while three were varied. In this way the minimum temperature for complete melting in each plane was determined. Data for a number of these planes were then employed to locate the quinary invariant point, which was found to have the composition, $1.0 \mathrm{Na}_{2} \mathrm{O}, 48.0 \mathrm{CaO}, 31.0 \mathrm{Al}_{2} \mathrm{O}_{3}, 13.5 \mathrm{Fe}_{2} \mathrm{O}_{3}$ and 6.5 percent of $\mathrm{SiO}_{2}$. At this point the five crystalline phases, $\mathrm{Na}_{2} \mathrm{O} .8 \mathrm{CaO} .3 \mathrm{Al}_{2} \mathrm{O}_{3}, 3 \mathrm{CaO} . \mathrm{Al}_{2} \mathrm{O}_{3}, \mathrm{Fe}_{2} \mathrm{O}_{3}$-containing solid solution, $2 \mathrm{CaO} . \mathrm{SiO}_{2}$, and $3 \mathrm{CaO} . \mathrm{SiO}_{2}$ exist in equilibrium with liquid.

The temperature of the invariant point was found to be $1,310^{\circ} \pm 3^{\circ} \mathrm{C}$. Compositions including the five constituents and approximating that of portland cement clinker will crystallize completely, upon slow cooling, at or near $1,310^{\circ} \mathrm{C}$. The stable existence of the soda compound $\mathrm{Na}_{2} \mathrm{O} .8 \mathrm{CaO} .3 \mathrm{Al}_{2} \mathrm{O}_{3}$ in the presence of the principal components of clinker was established. The data obtained permit a closer approximation of the amount of glass in rapidly cooled clinker. Dicalcium silicate and the iron-containing phase were observed to exist in various forms of solid solution.

Application of an analytic method for locating and following compositions within the quinary system has likewise been made. Equations have been developed and examples are given for depicting specific planes and points within these planes in the quinary system without the necessity of using geometric relations. The graphic and analytic methods, however, complement each other and together serve as a convenient procedure for studying any system of five components.
\end{abstract}

\section{Introduction}

Phase-equilibrium studies on the components of portland cement clinker have proved invaluable in predicting compound composition, explaining chemical activity, and in improving manufacturing practices. The four major components (lime, alumina, ferric oxide, and silica) have been considered, but many of the systems including the minor components (the alkalies, titania, manganese, and others) still await investigation. It is

\footnotetext{
${ }_{1}$ Part of a dissertation submitted to the Board of University Studies of the Johns Hopkins University in conformity with the requirement for the degree of Doctor of Philosophy, granted in June 1947.

${ }^{2}$ Research Associate at the National Bureau of Standards, representing the Portland Cement Association Fellowship.
}

essential, therefore, to extend phase-equilibrium studies of this important material to include additional components and crystallization products.

The presence of soda in portland cement has long been recognized, but the part it plays in the complex cement systems has not yet been fully defined. In the present study the role of $\mathrm{Na}_{2} \mathrm{O}$ is examined in a portion of the system N-C-A-F-S, ${ }^{3}$ including the composition range of portland

\footnotetext{
3 For convenience, the otherwise cumbersome formulas of the compounds encountered in this investigation are given in the following abbreviated forms: $\mathrm{N}=\mathrm{Na}_{2} \mathrm{O}$,

$\mathrm{C}=\mathrm{CaO}$,

$\mathrm{A}=\mathrm{Al}_{2} \mathrm{O}_{3}$,

$\mathrm{F}=\mathrm{Fe}_{2} \mathrm{O}_{3}$,$$
\mathrm{S}=\mathrm{SiO}_{2} \text {. }
$$

Thus $\mathrm{NC}_{8} \mathrm{~A}_{3}=\mathrm{Na}_{2} \mathrm{O} .8 \mathrm{CaO} .3 \mathrm{Al}_{2} \mathrm{O}_{3}$.
} 
cement. This investigation marks the first attempt, so far as is known, to study systematically and simultaneously the relations of these five components to each other.

Methods for defining the phase-equilibrium relations in binary, ternary, and quaternary systems are well known and have been extensively applied, but with systems of more than four components the difficulty of geometrical representation has severely restricted investigation. It has been customary in the treatment of quaternary systems to select regions that may be reduced to two or three components. In the present study a method is presented for the treatment of a five-component system by graphic methods and also by an analytic treatment developed in this laboratory.

The means of studying quinary systems is of particular interest for an understanding of the constitution not only of portland cement clinker but also of natural rocks and ceramic products, including glasses. The methods herein described for a study of the particular quinary system $\mathrm{NC}_{8} \mathrm{~A}_{3}-\mathrm{C}-\mathrm{C}_{5} \mathrm{~A}_{3}-\mathrm{C}_{2} \mathrm{~F}-\mathrm{C}_{2} \mathrm{~S}$ are of a general nature and may be applied to the study of other systems.

A brief review will first be given of the boundary systems previously investigated, followed by the description of the methods employed in this investigation and the results obtained. It should be pointed out that this study has been mainly exploratory, and that a more complete study of the system is a matter for future investigation.

\section{Previous Work on Boundary Systems}

Of the five quaternary systems bounding the quinary system N-C-A-F-S, one (N-A-F-S) contains no $\mathrm{CaO}$ and is not considered significant in this study. A portion of the system C-A-F-S covering the region $\mathrm{C}-\mathrm{C}_{5} . \mathrm{A}_{3}-\mathrm{C}_{4} \mathrm{AF}-\mathrm{C}_{2} \mathrm{~S}$ was reported in 1934 by Lea and Parker [1] ${ }^{4}$ and, more recently, the region $\mathrm{C}-\mathrm{C}_{5} \mathrm{~A}_{3}-\mathrm{C}_{2} \mathrm{~F}-\mathrm{C}_{2} \mathrm{~S}$ was examined by Swayze [2]. A portion of the system $\mathrm{N}-\mathrm{C}-\mathrm{A}-\mathrm{S}$ covering the region N.A-C-A-C $\mathrm{C}_{2} \mathrm{~S}$ was investigated by Greene and Bogue [3]. Some preliminary studies on the system N-C-A-F in the regions $\left(\mathrm{NA}_{3}\right)-\mathrm{C}-\mathrm{C}_{4} \cdot \mathrm{AF}$ and $\mathrm{N}-\mathrm{C}-\mathrm{C}_{5} \cdot \mathrm{A}_{3}-\mathrm{C}_{2} \mathrm{~F}$ and on the system N-C-F-S in the region N-C-CF-C ${ }_{2} \mathrm{~S}$ were reported recently by Eubank and Bogue [4].

\footnotetext{
4 Figures in brackets indicate the literature references at the end of this paper.
}

Temperatures ${ }^{5}$ and compositions of certain invariant points determined in these boundary systems are given in table 1.

Throughout this investigation the phase containing iron is designated by the short notation Fss indicating an $\mathrm{Fe}_{2} \mathrm{O}_{3}$-containing solid solution, and for brevity is called the "iron phase." A more quantitative but longer formula for this solidsolution phase is $\mathrm{C}_{6} \cdot \mathrm{A}_{x} \mathrm{~F}_{3-x}$, with $x$ varying from 0 to 2 . This represents any composition in a series of solid solutions extending from $\mathrm{C}_{2} \mathrm{~F}$ to $\mathrm{C}_{6} \mathrm{~A}_{2} \mathrm{~F}$. These solid solutions have been reported by Swayze [2].

\section{Experimental Procedure}

The experimental procedure followed the quenching method as described by Bogue [5] with certain modifications. Identification of phases in the quenched charges was made with the petrographic microscope.

Because of the difficulty in obtaining sufficiently rapid cooling to form identifiable crystals, very small charges weighing only a few milligrams were used. Quenching in water, mercury, and liquid air was tried. Mercury did not prove satisfactory, because the charge floated on it with only its underside cooling rapidly. Good quenching resulted in liquid air, even though this has a lower heat capacity than water. Satisfactory results were obtained by quenching very small charges in water. Hydration of the quenched charge was not enough to interfere with petrographic observations.

Platinum envelopes (closed containers), and platinum pans (open containers) as used by Swayze [2], were compared. Loss of soda by volatilization at high temperatures was found to be greater in the case of the open pans. Therefore platinum envelopes were generally used but were reduced to the very small size of 2 to $3 \mathrm{~mm}$ square.

An arrangement was employed by means of which two charges of different composition could be quenched simultaneously at a particular temperature. Two pairs of heavy L-shaped platinum leads at the bottom of the quenching assembly were used to suspend, by means of fine platinum wire, two platinum envelopes on opposite

\footnotetext{
${ }^{3}$ All temperatures are given in degrees Centigrade. Temperature values determined in this study are considered reliable to within \pm 3 deg; however, temperatures could be controlled to within $\pm 0.1 \mathrm{deg}$.
} 
sides of the thermocouple junction. The voltage necessary to melt both fine suspension wires was applied at the top of the assembly. Two battery clips, each connecting one lead of each pair, made double quenching possible. This allowed the investigation to proceed more rapidly than is possible in a single-quench operation.

It was found convenient to have a thermocouple mounted in the furnace slightly below the level of the quenching assembly. The temperature of the furnace could then be read and adjusted to the desired value before the charges were introduced. A second thermocouple within the quenching assembly was used for precise temperature measurement. This thermocouple was recalibrated frequently against an NBS standard thermocouple or the melting point of pure $\mathrm{BaO} \cdot 2 \mathrm{SiO}_{2}$ (m. p. 1,418 ${ }^{\circ}$ [6]. A method of precise temperature control making use of a thyratron quenchingfurnace thermostat [7] was developed for this investigation.

The cement compounds and base mixes used in this study were prepared from oxides or carbonates of unusually high purity. Two of these specially prepared starting materials, ferric oxide and silica gel, were of better than 99.99-percent purity by spectrographic analysis. Chemical analysis showed that the sodium and calcium carbonates contained a maximum of 0.04 percent of impurity and that the alumina contained no more than 0.10 percent of impurity. All compounds were ground in a mullite mortar to pass a No. 200 U. S. Standard Sieve. Compositions were dry-ground to insure thorough mixing. Homogeneity was checked by microscopic examination.

The practice of making powder-slides of important charges using Hyrax resin, refractive index 1.715, was continued [4], because this index is very close to that of several cement compounds. Restudy of these permanent specimen-preparations could then conveniently be made.

\section{Methods for Studying a Quinary System}

Two means, one graphic and the other analytic, may be used in tracing the phase-equilibrium relations in a system of five components. The first of these, the graphic method, was used for the most part in this study. The analytic method was developed by Dahl $[8,9]$ subsequent to the use of the graphic method. Both methods will be presented and their applications discussed.

\section{Graphic Method}

Phase studies in a quaternary system are usually made with a series of triangular sections (diagrams) through a tetrahedron. These may be located in the tetrahedron by choosing various ratios of two of the componenis and holding these constant for each plane (triangular diagram) or, as is more often the case, planes parallel to the base with a constant amount of the fourth component in each plane may be studied, allowing the other three components to vary. Each plane will represent the intersection of that plane with one or more primary-phase volumes. Invariant points are likely to be located between planes, since the choice of a plane with the exact amount of the fourth component for an invariant point would be accidental. Such points would have to be extrapolated from the data obtained for the planes above or below it, or additional planes between the two might be studied.

The best means for beginning the investigation of the quinary system would seem to be that of first studying the corresponding invariant points in the boundary quaternary systems. Some of these invariant points [4] were determined preliminary to the study of this quinary system. A small tetrahedron, 20 percent on a side, was chosen containing the compositions of these invariant points for the boundary quaternary systems, for example, $T_{1}$ and $T_{2}$, figure 1 [1]. For

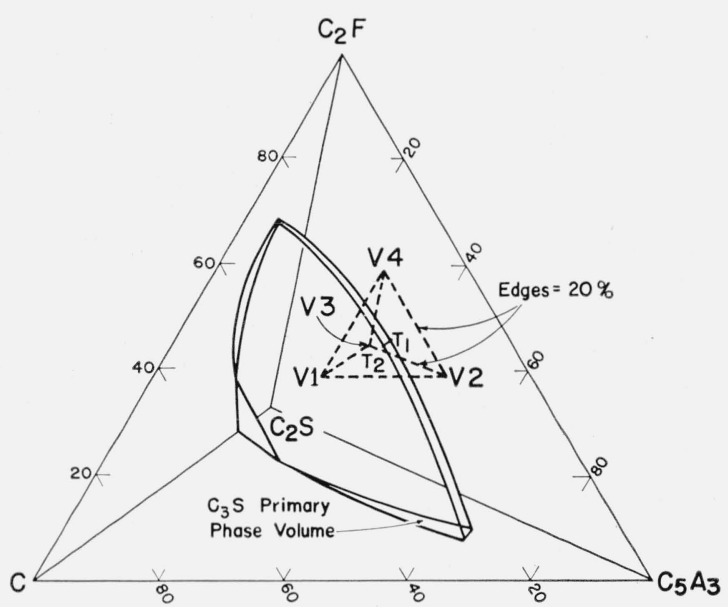

Figure 1. Location of a small tetrahedron containing quaternary invariant points [1]. 


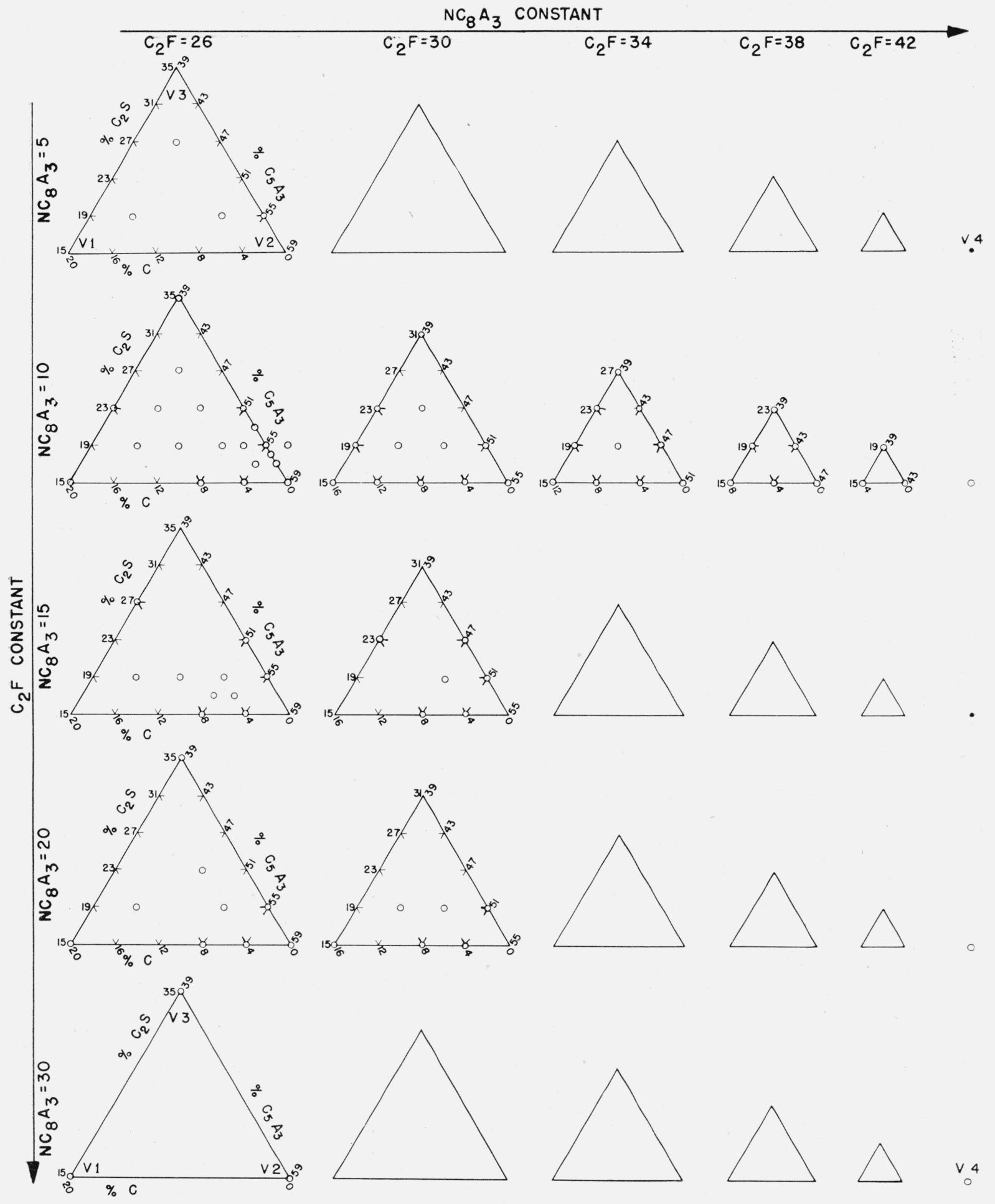

FIgURE 2. Circled points represent compositions studied within the quinary system $\mathrm{NC}_{8} \mathrm{~A}_{3}-\mathrm{C}-\mathrm{C}_{5} \mathrm{~A}_{3}-\mathrm{C}_{2} \mathrm{~F}-\mathrm{C}_{2} \mathrm{~S}$.

Only $\mathrm{NC}_{8} \mathrm{~A}_{3}$ is given as a quinary composition. The remaining four components are given as the quaternary components of figure 1 . When $X$ percent of $\mathrm{NC}_{8} \mathrm{~A}_{3}$ was added, the percentage of each of the four quaternary components was multiplied by $(100-X) / 100$ to bring all compositions within the quinary system. For example, a particular point in the $10 \mathrm{NC}_{8} \mathrm{~A}_{3}-26 \quad \mathrm{C}_{2} \mathrm{~F}$ plane will contain 10 percent of $\mathrm{NC}_{8} \mathrm{~A}_{3} 0.90 \times 26$ percent of $\mathrm{C}_{2} \mathrm{~F}$, and $0.90 \times \mathrm{C}_{2}$ percentages of the other three indicated in the triangular diagram. 
points located in this tetrahedron, $X$ percent of the fifth component would be added and $100-X$ percent taken of the remaining four. This would bring the compositions to be studied within the quinary system. Both oxide and compound compositions at the vertices of this small tetrahedron to which soda is to be added are given in the following tabulation.

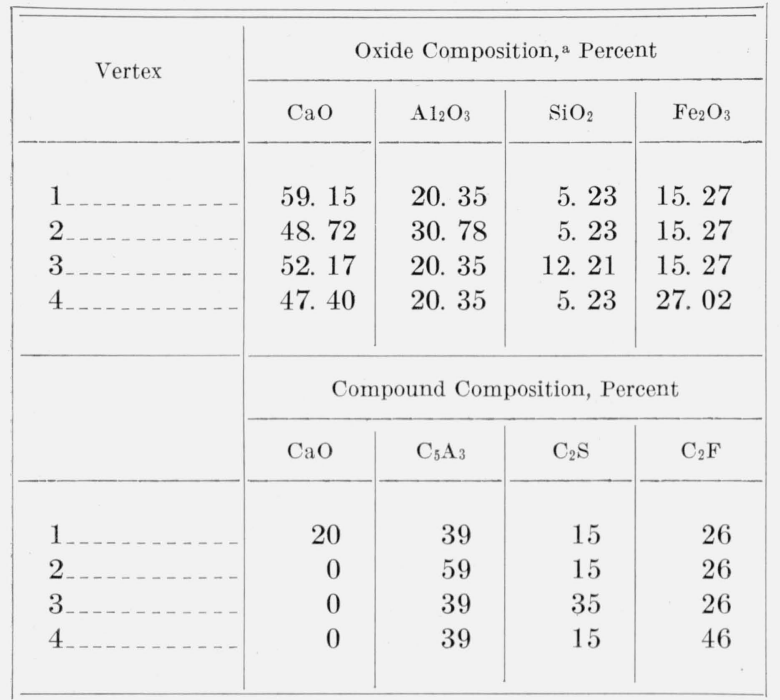

a All compositions referred to in this work are given in weight percent.

Compositions in the quinary system may be followed by the two series of planes (triangular diagrams) shown in figure 2. In the first series the iron phase is allowed to vary, whereas in the second the soda phase is varied. In each particular plane both the iron phase and soda are maintained constant and the other three components allowed to vary. The composition melting at the lowest temperature in each plane locates a point on a bivariant surface in the quinary system. The locus of these points for each series of planes intersects a univariant curve. This intersection, usually a directional change point, may be located by plotting the various components or ratios of the components for a number of intersection points. It is not likely that this point of intersection will be on any plane chosen, but it will occur between planes and can thus be estimated by the extension of the curves. A number of these intersection points will define a univariant curve that may be followed to the invariant point.

Visualization of the relations between a large number of bivariant surfaces is limited by con- ventional three-dimensional representation. It is possible, however, to show diagrammatically the relations between such surfaces at a single invariant point, as is shown in figure 3. Five univariant curves meet at an invariant point. These are boundaries of the bivariant surfaces intersecting at that point. The number of curves and surfaces meeting at the invariant point and the number of solid phases represented for each meet the requirements of the phase rule for a

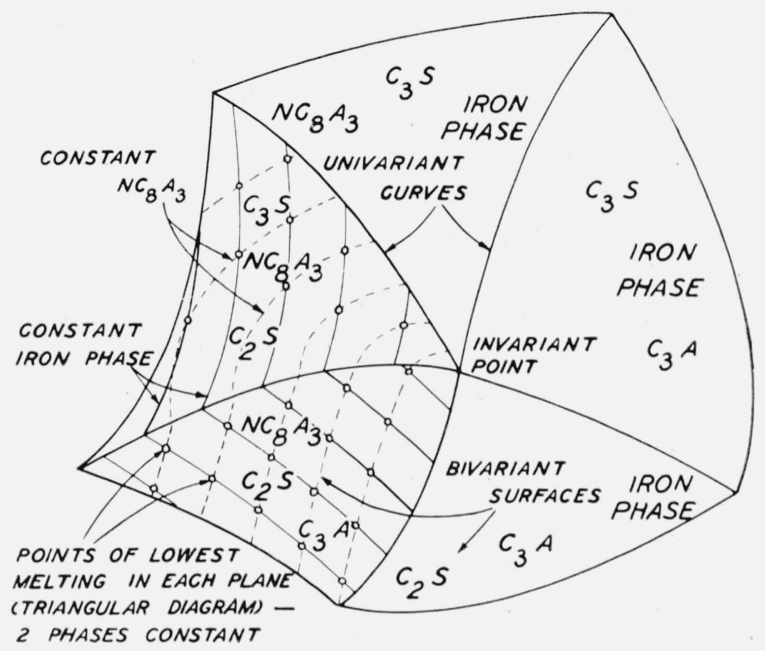

Figure 3. Successive percentages of the iron phase are shown along the solid lines on the bivariant surface at the left.

Successive percentages of the soda phase are represented by dashed lines. The intersections of these two sets of lines represent the composition point of the lowest temperature for complete melting determined for each plane when both the iron and soda phases were held constant. A univariant curve is the locus of points of directional change in the curves representing constant $\mathrm{NC}_{8} \mathrm{~A}_{3}$ or constant iron phase. A univariant curve may then be followed to the quinary invariant point.

condensed system. Five solid phases are in equilibrium with liquid at the invariant point. Five univariant curves along which four solid phases are in equilibrium with liquid intersect at this point. Five bivariant surfaces on which three solid phases are in equilibrium with liquid meet at the invariant point. The volumes bounded by these surfaces may be considered trivariant with two solid phases in equilibrium with liquid. The tetravariant primary-phase regions for the five solid phases cannot be shown in a conventional space model. Phase-equilibrium relations at a quinary invariant point are pictured arbitrarily in figure 3. 
Each triangle in figure 2 is analogous to a straight line in the space model of a quaternary system A-B-C-D, parallel to one of the edges, thus fixing the percentages of two of the components of the system. Such a line may be represented by two equations, for example, $A=5$ and $C=45$. It is apparent that the line may not intersect any univarant curve and that it will intersect a bivariant surface at only one point. Similarly, a quaternary system within a quinary system may be represented by an equation, and a ternary system within a quinary system may be represented by two equations. Interpretation of the data obtained from the triangles in figure 2 requires a knowledge of the manner in which invariant points, univariant curves, etc., in a quinary system appear in triangular diagrams. The following tabulation shows how these relations in a quinary system appear in a triangular diagram and a space model (tetrahedron), according to Dahl [10].

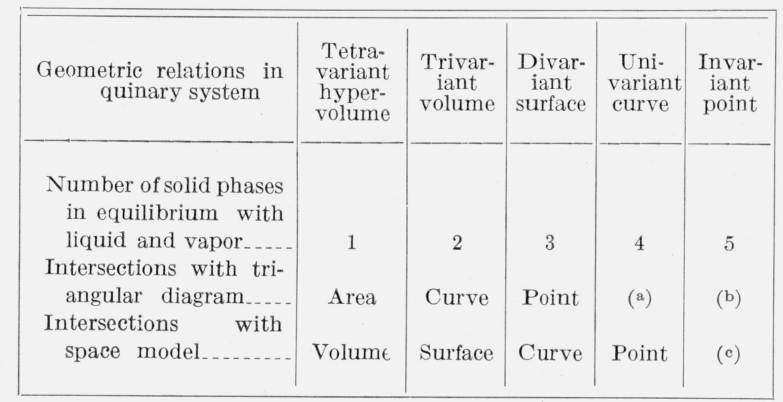

a May appear as a point in the triangular diagram, but only when both of the two equations of the triangular diagram are satisfied by some point on the univariant curve. The point in the diagram then represents that particular point.

b May appear as a point in the triangular diagram, but only when both of the two equations of the triangular diagram are satisfied by the invariant point.

c May appear as a point in a space model, but only when the equation of the space model is satisfied by the invariant point.

\section{Analytic Method}

In representing phase-equilibrium relations of a quinary system within a triangular diagram or space model, conditions are imposed that indicate the manner in which compositions in these figures are different from all other compositions in the quinary system. A set of intrinsic equations, that is, equations involving components of a system and lacking a constant term, may be used to express these conditions. For example, in dealing with the system $\mathrm{NC}_{8} \mathrm{~A}_{3}-\mathrm{C}-\mathrm{C}_{5} \mathrm{~A}_{3}-\mathrm{C}_{2} \mathrm{~S}-\mathrm{C}_{2} \mathrm{~F}$, it may be decided to work for a time with compositions limited to 10 percent of $\mathrm{C}_{2} \mathrm{~F}$. A space model (tetrahedron) may be used to represent the composition relations under this condition, since the sum of the percentages of the remaining components is constant. The equation of the space model is $\mathrm{C}_{2} \mathrm{~F}=10$. When the percentages of two of the components are fixed, for example if $\mathrm{C}_{2} \mathrm{~F}=10$ and $\mathrm{NC}_{8} \mathrm{~A}_{3}=5$, the sum of the remaining components is 85 percent, and relations between the remaining components may be shown in a triangular diagram.

Dahl has recently published a paper on the analytic treatment of multi-component systems using intrinsic equations [9]. This has been followed by another paper [8] on the properties and application of parametric equations. Dahl's equations are derived directly in terms of composition without considering geometric relations and may be applied to multi-component systems without the necessity of thinking in terms of hyperspace.

The number of intrinsic equations required to define a secondary system of $m$ components in a primary system of $N$ components is equal to the difference $N-m$. For example, a binary system is represented by a single equation when it is in a ternary system but requires three equations if it is in a quinary system. The number of terms that may appear in the equations also increases with the complexity of the system. A binary system within a quinary system may, however, be expressed by parametric equations using only one parameter. A ternary system requires two parameters, and so on. Parametric equations may therefore be used to define binary and ternary systems within a quinary system and intrinsic equations may be used in defining the more complicated quaternary systems within a quinary system. Thus, both types of equations may be employed in defining relations in a quinary system. The intrinsic equations may be set up in the manner of Dahl by using algebraic and determinant methods in connection with oxide or compound formulas and their molecular weights.

A parameter is introduced in order to express the composition of each component in terms of that variable. To define a system of $m$ components in an $N$-component system, $N$ parametric equations and $m-1$ parameters are required. To illustrate 
the procedure as applied to systems requiring more than one parameter, the ternary system $\mathrm{NC}_{8} \mathrm{~A}_{3}-\mathrm{C}_{4} \mathrm{AF}-\mathrm{C}_{3} \mathrm{~S}$ may be defined within the quinary system, N-C-A-F-S. The data needed are the compositions of the components of the ternary system as calculated from their molecular weights. Two parameters are required. This is illustrated in the following tabulation, in which the parameters are $r$ and $s$. The weight fraction of $\mathrm{NC}_{8} \mathrm{~A}_{3}$ is $r$, that of $\mathrm{C}_{4} \mathrm{AF}$ is $s$, and that of $\mathrm{C}_{3} \mathrm{~S}$ is $1-r-s$. Thus, by varying $r$ and $s$ between 0 and 1 , with $r+s$ not exceeding 1 , compositions in any part of the ternary system $\mathrm{NC}_{8} \mathrm{~A}_{3}-\mathrm{C}_{4} \mathrm{AF}-\mathrm{C}_{3} \mathrm{~S}$ within the quinary system N-C-A-F-S can be located and studied. The sum of the parametric expressions in the equations must be equal to 100 percent.

\begin{tabular}{|c|c|c|c|c|}
\hline $\begin{array}{c}\text { Primary } \\
\text { component }\end{array}$ & $\mathrm{NC}_{8} \mathrm{~A}_{3}$ & $\mathrm{C}_{4} \mathrm{AF}$ & $\mathrm{C}_{3} \mathrm{~S}$ & Parametric equation \\
\hline $\begin{array}{l}\mathrm{N} \\
\mathrm{C} \ldots \\
\mathrm{A} \\
\mathrm{S} \ldots \\
\mathrm{F}_{\ldots}\end{array}$ & $\begin{array}{c}\text { Percent } \\
7.6 \\
54.9 \\
37.5 \\
-. .- \\
-.-\end{array}$ & $\begin{array}{c}\text { Percent } \\
-\ldots .2 \\
46.2 \\
20.9 \\
-\ldots 2.9 \\
32 .\end{array}$ & \begin{tabular}{c} 
Percent \\
-73.7 \\
\hdashline 26.3 \\
$\ldots .$.
\end{tabular} & $\begin{array}{l}\mathrm{N}=7.6 r . \\
\mathrm{C}=18.8 r-27.5 s+73.7 . \\
\mathrm{A}=37.5+r 20.9 s . \\
\mathrm{S}=26.3 r-26.3 s+26.3 . \\
\mathrm{F}=\quad 32.9 s .\end{array}$ \\
\hline $\begin{array}{l}\text { Weight frac- } \\
\text { tion }\end{array}$ & $r$ & 8 & $(1-r-8)$ & \\
\hline
\end{tabular}

Parametric equations may be used to trace compositions in planes within the quinary system. This serves the same purpose as the series of planes described in the graphic method, but without the necessity of considering geometric relations. For this study compositions in the quinary system are confined to a subordinate system in which the components are those at the vertices of the small tetrahedron in figure 1 , with $\mathrm{NC}_{8} \mathrm{~A}_{3}$ as the fifth component. The first step in the analytic method is to obtain parametric equations in which the percentage of each component of the quinary system is expressed in terms of weight fractions of components of the subordinate system. This is shown in the tabulation below.

\begin{tabular}{|c|c|c|c|c|c|c|}
\hline \multirow{2}{*}{$\begin{array}{l}\text { Composition } \\
\text { points of sub- } \\
\text { ordinate } \\
\text { system }\end{array}$} & A & B & $\mathrm{C}$ & D & $\mathrm{E}$ & \multirow{2}{*}{ Weight fraction } \\
\hline & $\mathrm{CaO}$ & $\mathrm{C}_{2} \mathrm{~S}$ & $\mathrm{C}_{5} \mathrm{~A}_{3}$ & $\mathrm{C}_{2} \mathrm{~F}$ & $\mathrm{NC}_{8} \mathrm{~A}_{3}$ & \\
\hline & $\%$ & $\%$ & $\%$ & $\%$ & $\%$ & \\
\hline V1 & 20 & 15 & 39 & 26 & 0 & $v$ \\
\hline $\mathrm{V} 2$ & 0 & 15 & 59 & 26 & 0 & $w$ \\
\hline V3 & 0 & 35 & 39 & 26 & 0 & $x$ \\
\hline V4 & 0 & 15 & 39 & 46 & 0 & $y$ \\
\hline V5 & 0 & 0 & 0 & 0 & 100 & $1-v-w-x-y$ \\
\hline
\end{tabular}

Quinary System $\mathrm{Na}_{2} \mathrm{O}-\mathrm{CaO}-\mathrm{Al}_{2} \mathrm{O}_{3}-\mathrm{Fe}_{2} \mathrm{O}_{3}-\mathrm{SiO}_{2}$
Equations for the quinary system are:

$$
\begin{aligned}
& \mathrm{A}=20 v, \\
& \mathrm{~B}=15 v+15 w+35 x+15 y, \\
& \mathrm{C}=39 v+59 w+39 x+39 y, \\
& \mathrm{D}=26 v+26 w+26 x+46 y, \\
& \mathrm{E}=-100 v-100 w-100 x-100 y+100 .
\end{aligned}
$$

Parametric equations for a ternary system (triangular diagram) require only two parameters, and the second step is to eliminate two of the parameters in eq 1 to 5 . These parameters may be selected arbitrarily, and in this case $x$ and $y$ are chosen. Since $\mathrm{C}_{2} \mathrm{~F}$ and $\mathrm{NC}_{8} \mathrm{~A}_{3}$ are to be maintained constant in each triangle, as in figure 2 , it will be assumed that $D$ and $E$ are equal to the constants $D_{1}$ and $E_{1}$, respectively. Transposing eq 4 and 5 , and simplifying, the following equations are obtained:

$$
\begin{aligned}
26 x+46 y & =D_{1}-26 v-26 w, \\
x+y & =-0.01 E_{1}-v-w+1 .
\end{aligned}
$$

Solving for $x$ and $y$,

$$
\begin{aligned}
& x=-0.05 D_{1}-0.023 E_{1}-v-w+2.3, \\
& y=0.05 D_{1}+0.013 E_{1} \quad-1.3 .
\end{aligned}
$$

Substituting in eq 1 to 3 ,

$$
\begin{aligned}
& A=20 v \\
& B=-20 v-20 w+0.61\left(100-E_{1}\right)-D_{1}, \\
& C=\quad 20 w+0.39(100-E) .
\end{aligned}
$$

Upon substituting in eq 8 to 10 , the values of $D_{1}$ and $E_{1}$ to be maintained constant in any given triangle, equations for $A, B$, and $C$ will be obtained in terms of the parameters $v$ and $w$. For example, if $D_{1}$ and $E_{1}$ (that is, $\mathrm{C}_{2} \mathrm{~F}$ and $\mathrm{NC}_{8} \mathrm{~A}_{3}$ ) are to be given the values 23.4 and 10.0 percent, respectively, substitution of these values in eq 8 to 10 yields the following equations for compositions in the triangle.

$$
\begin{aligned}
& A=20 v, \\
& B=-20 v-20 w+31.5, \\
& C=\quad 20 w+35.1 .
\end{aligned}
$$


Substitution of 23.4 and 10.0 for $D_{1}$ and $E_{1}$, respectively, in eq 6 leads to the equation,

$$
x=0.9-v-w .
$$

Since the weight fractions of the subordinate components cannot be negative, $(v+w)$ in the triangle under consideration cannot exceed 0.9.

Thus, by varying the weight fractions $v$ and $w$, within the limits specified, any composition of the ternary system in which $D=23.4$ and $E=10$ within the quinary system may be obtained. For example, the test composition $10 \mathrm{~N} 26 \mathrm{~F} 5$, discussed later and given in table 4 , is located within this plane when $v=0$ and $w=0.72$ and can then be studied. Additional parametric equations for other planes and points within planes may be found in a similar manner. The lowest melting composition for each plane is then determined experimentally. As described earlier, the locus of these points crosses a univariant curve, which may then be traced to the invariant point.

\section{Results}

The compositions studied by use of the graphic method are indicated by the circled points in the two series of triangular diagrams given in figure 2 . These compositions, along with the quenching data and the results of petrographic examination, are given in tables 2 through 4 . Only the data necessary to locate the liquidus or to identify both primary and secondary phases are presented. For many compositions only one quench was required when it was obvious that the liquidus temperature was increasing, i. e., compositions were getting farther from the invariant point. In these cases the appearance of primary and secondary phases was more important than the location of the exact liquidus temperature.

TABLE 1. Invariant points for systems bounding the quinary system $\mathrm{NC}_{8} \mathrm{~A}_{3}-\mathrm{C}-\mathrm{C}_{5} \mathrm{~A}_{3}-\mathrm{C}_{2} \mathrm{~F}-\mathrm{C}_{2} \mathrm{~S}$

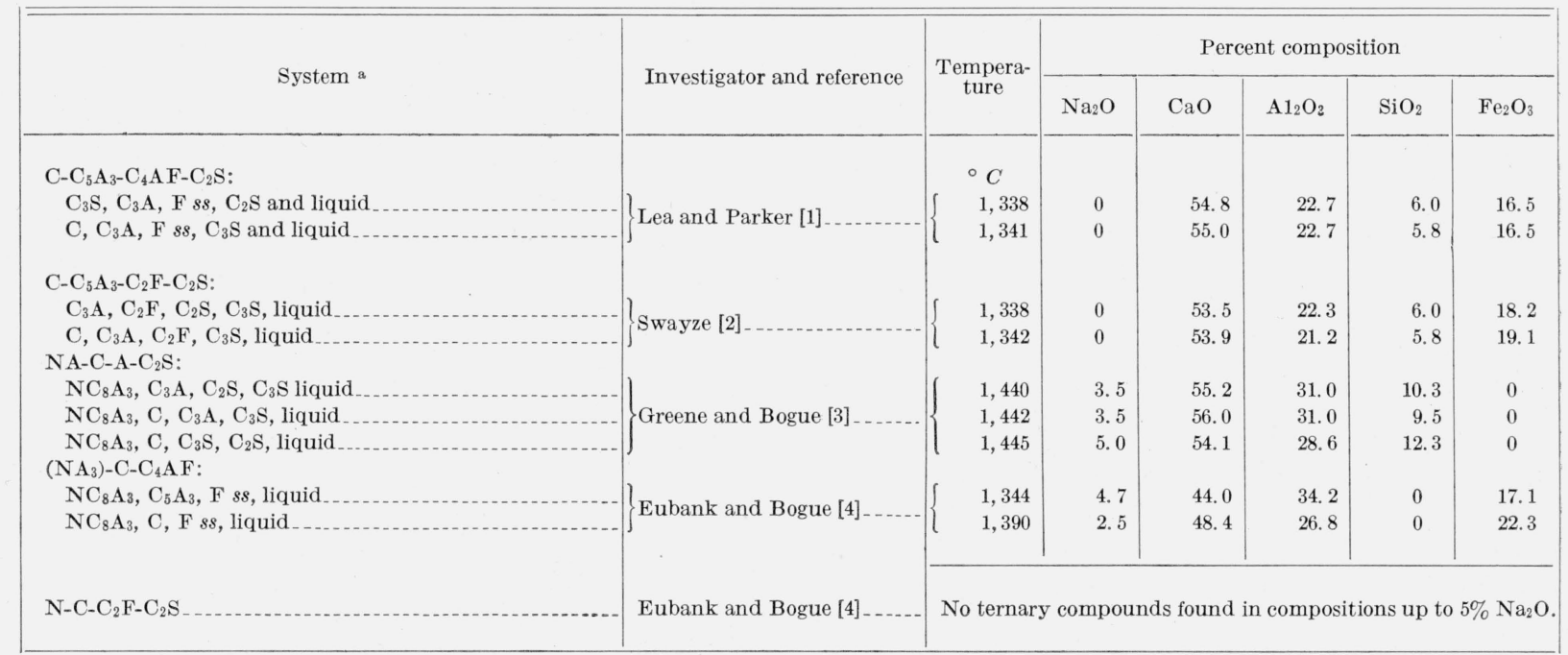

aFor convenience the otherwise cumbersome formulas of the compounds encountered in this investigation are given the following abbreviated forms: $\mathrm{N}=\mathrm{Na}_{2} \mathrm{O}, \mathrm{C}=\mathrm{CaO}, \mathrm{A}=\mathrm{Al}_{2} \mathrm{O}_{3}, \mathrm{~F}=\mathrm{Fe}_{2} \mathrm{O}_{3}$, and $\mathrm{S}=\mathrm{SiO}_{2}$. Thus $\mathrm{NC}_{8} \mathrm{~A}_{3}=\mathrm{Na}_{2} \mathrm{O} .8 \mathrm{CaO} .3 \mathrm{Al}_{2} \mathrm{O}_{3}$, etc. 
TABLE 2. Quenching data on quaternary invariant-point compositions with and without addition of soda

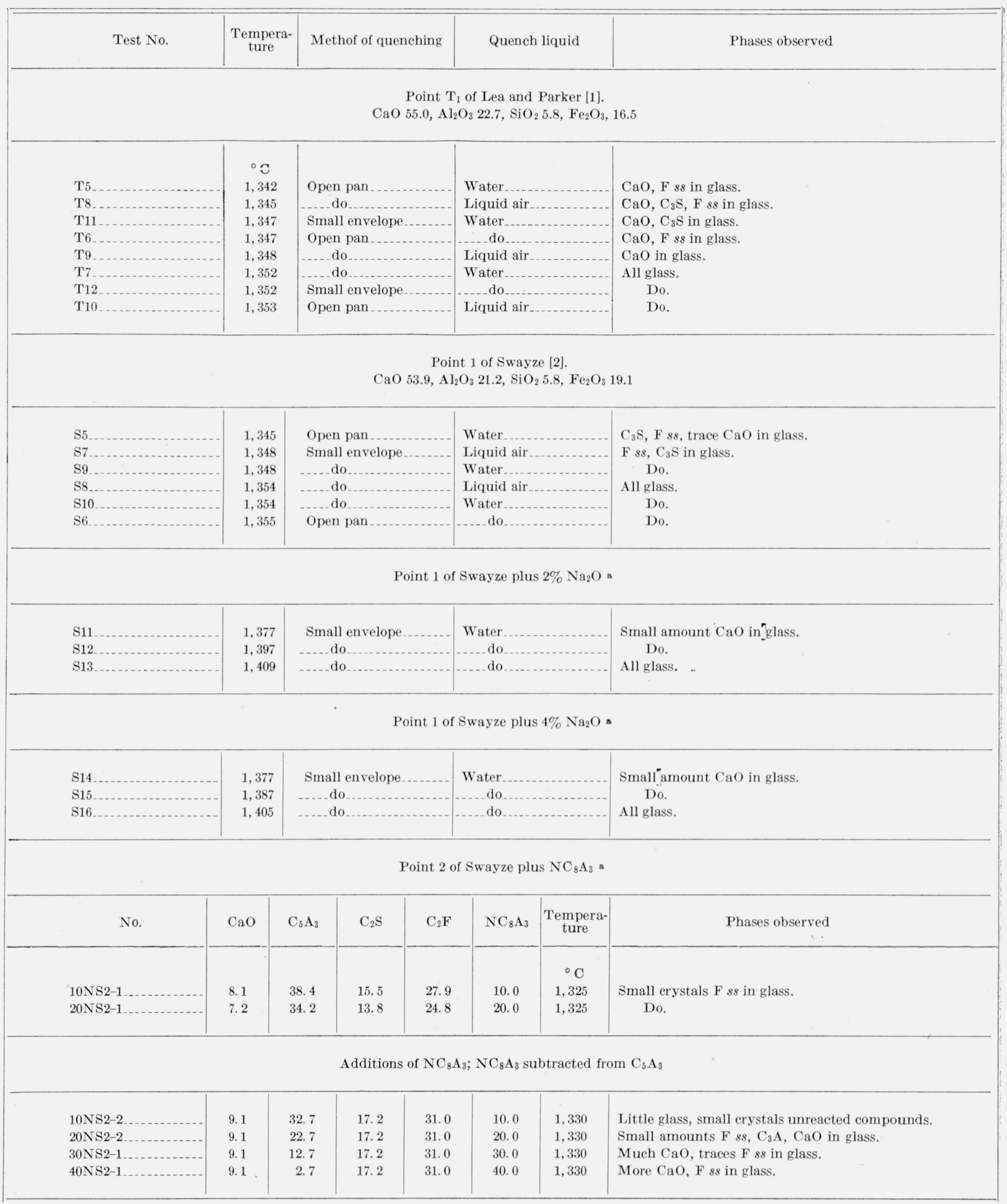

* When $x \%$ of soda phase was added, $(100-x) \%$ of each constituent of the quaternary composition point was taken. Unless otherwise stated, all quenches were made in small platinum envelopes into water. 
TABLE 3. Quenching data on boundaries of the small tetrahedron figure 1, with and without additions of soda

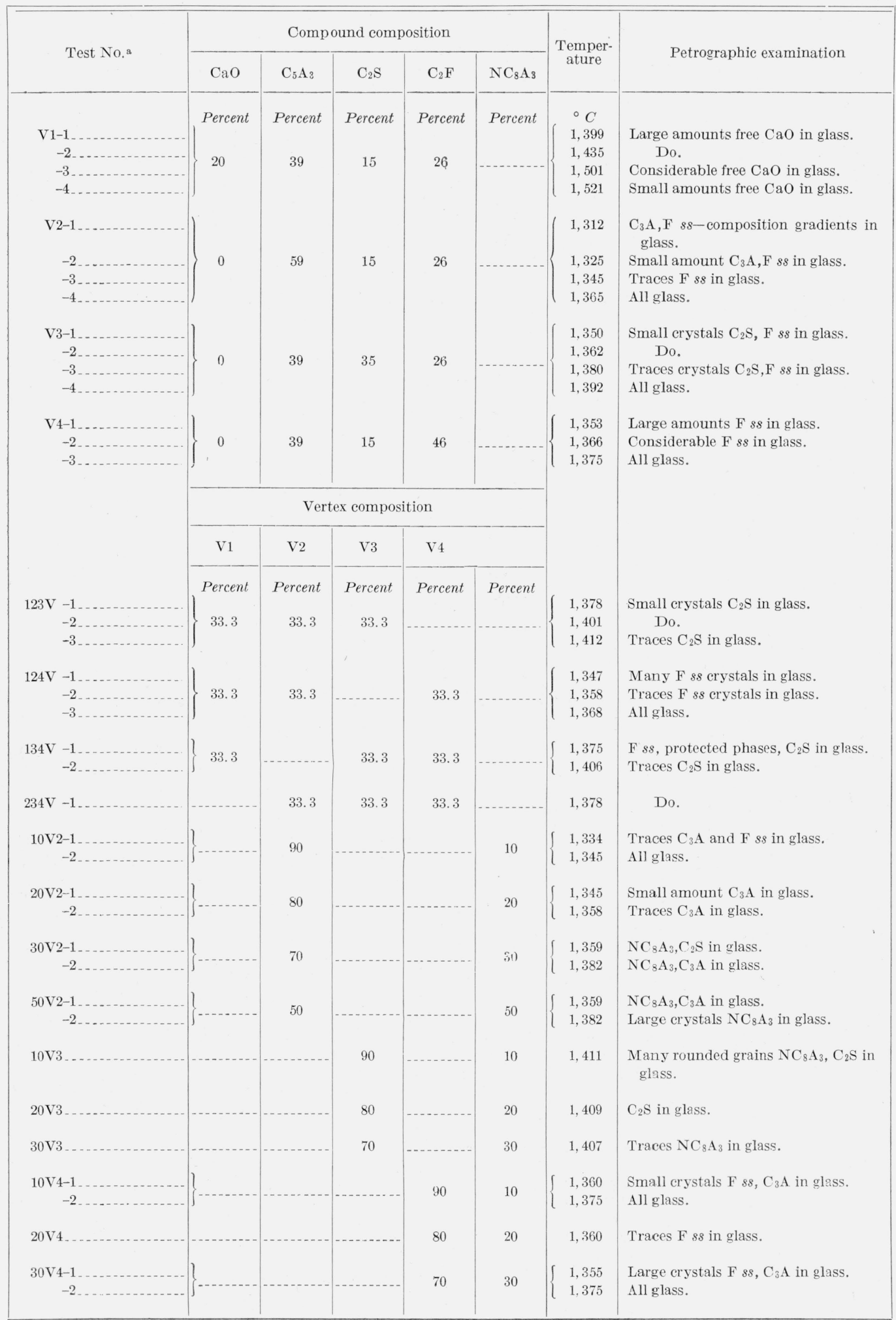

a $V$ refers to the vertices of the small tetrahedron of figure 1. 
TABLE 4. Quenching data on planes (fig. 2) within the quinary system

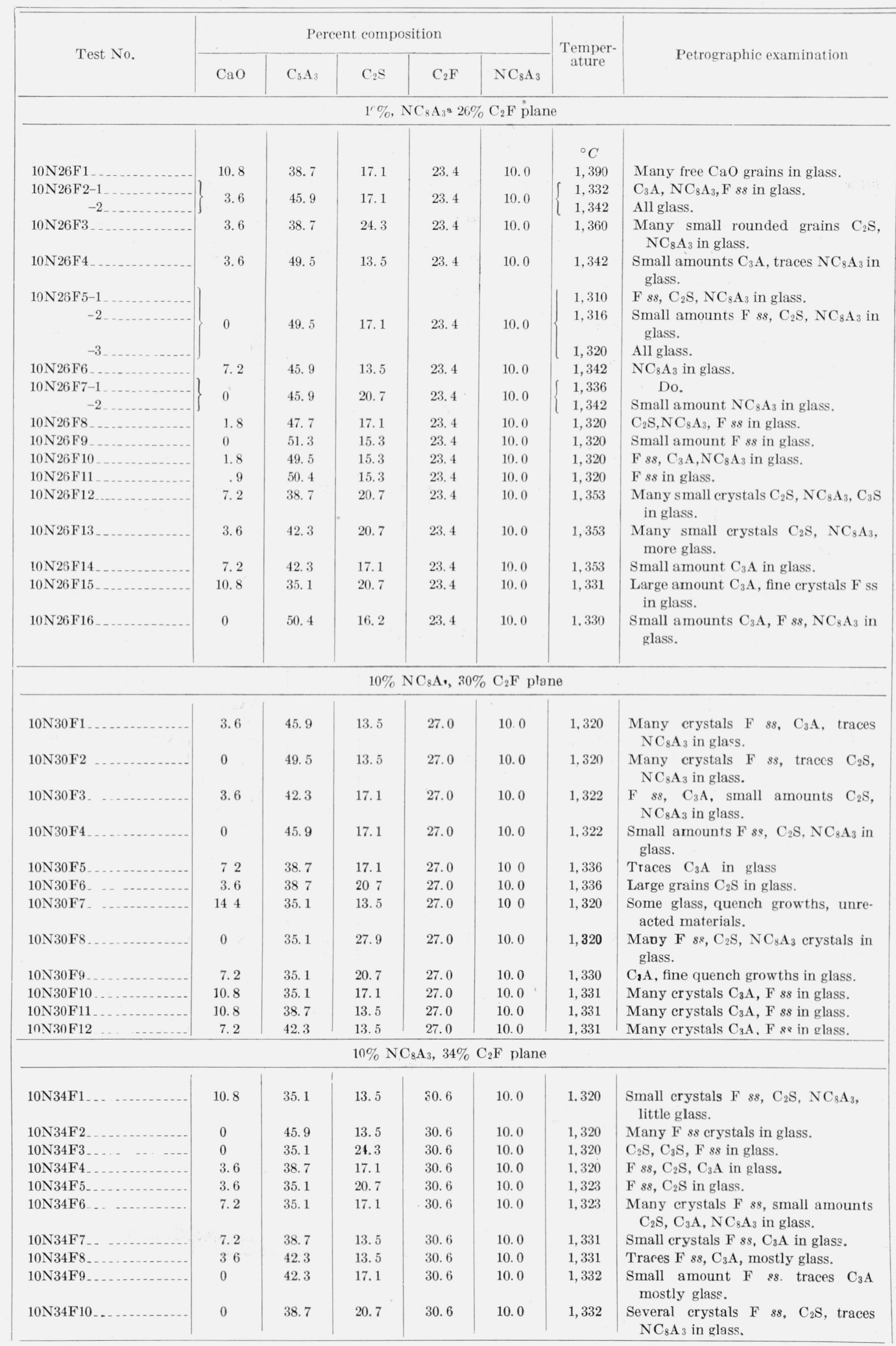

a When $\mathrm{X} \%$ of soda phase was added, $(100-\mathrm{X}) \%$ of each constituent of the quaternary composition point was taken. 
TABLE 4. Quenching data on planes (fig. 2) within the quinary system-Continued

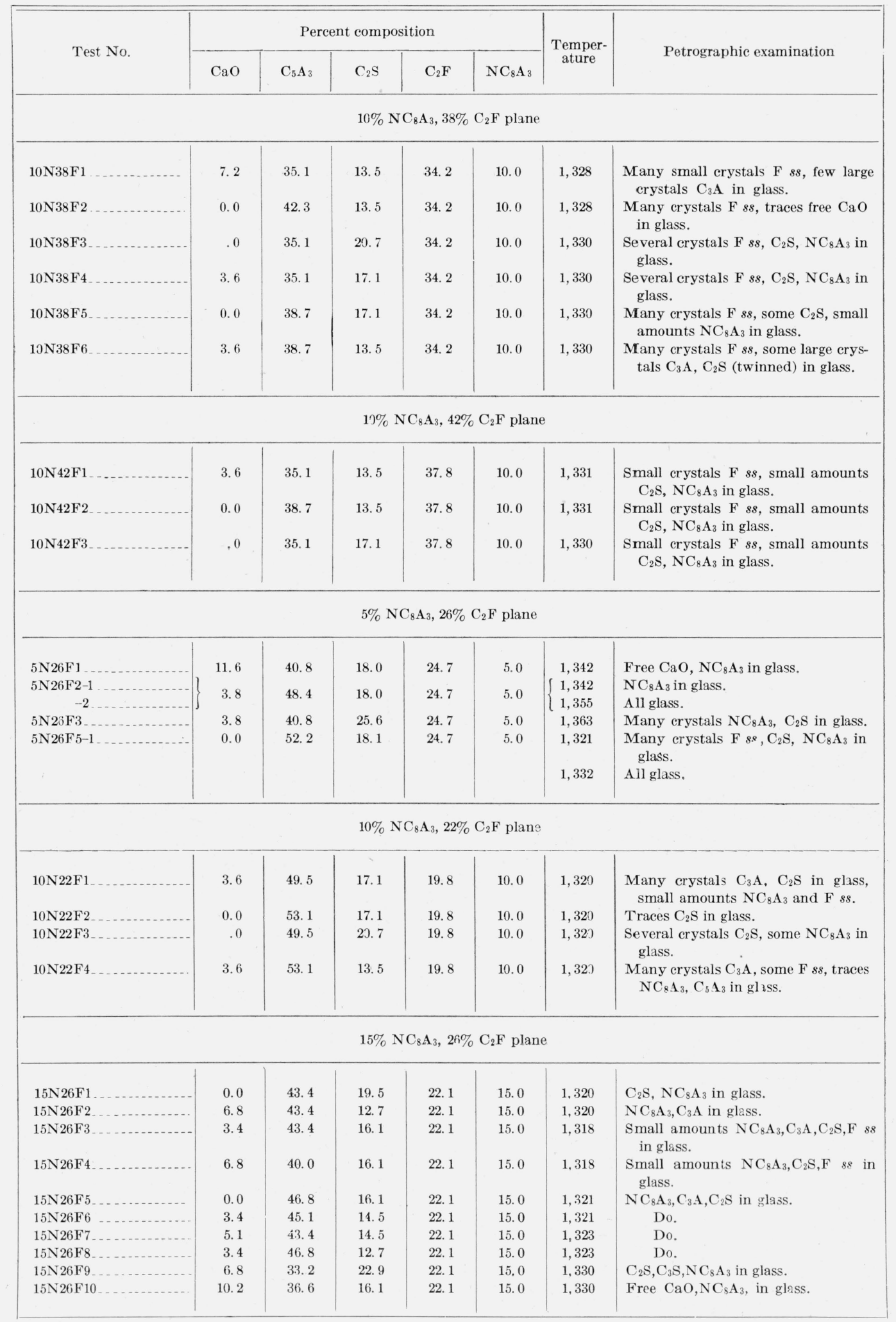


TABLE 4. Quenching data on planes (fig. 2) within the quinary system-Continued

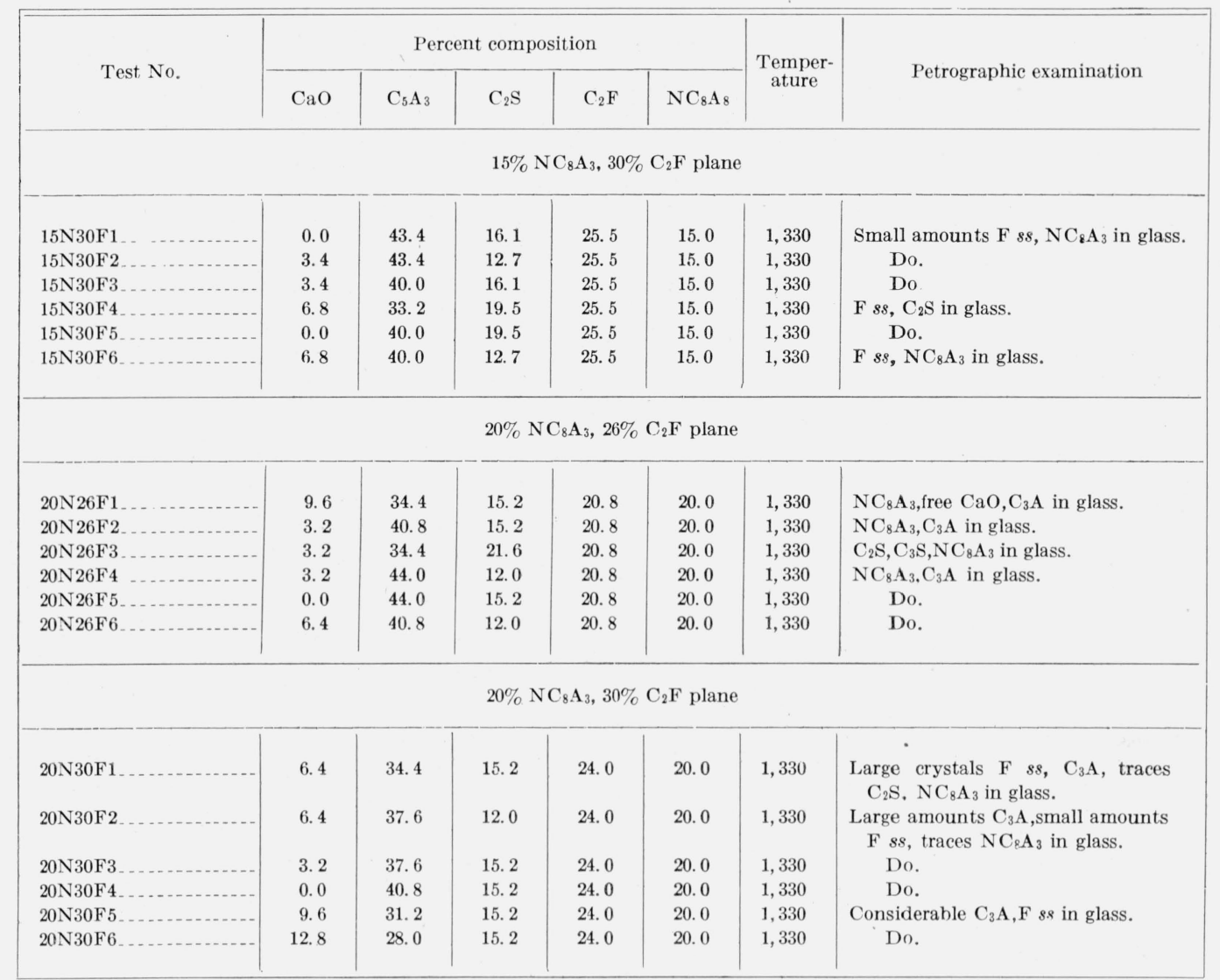

The procedure for locating invariant points within the quinary system may be followed systematically by reference to the above mentioned figure and tables. Selection of a small tetrahedron to which the fifth component, the soda phase, was to be added, was made by studying the relations in the boundary systems as discussed in conjunction with figure 1 .

Invariant points for the soda-free quaternary system have been reported by other investigators $[1,2]$. Lea and Parker's point $T_{1}$ and Swayze's point 1 were reported as invariant points at which $\mathrm{CaO}, \mathrm{C}_{3} \mathrm{~S}, \mathrm{C}_{3} \mathrm{~A}$, and iron phase are in equilibrium with liquid. Compositions for point $T_{1}$ and point 1 were investigated by the quenching methods described earlier, table 2 . The observed liquidus temperature was $1,350^{\circ} \mathrm{C}$ for each of these compositions. This is higher than the $1,341^{\circ}$ reported by Lea and Parker for composition $T_{1}$ and the $1,342^{\circ}$ reported by Swayze for point 1 . It is likely that these departures from the published data result from differences in the impurities of the reagents used by the several investigators. Since such variations produce slight changes in composition, the liquidus temperature obtained by the present author in the quaternary system cannot be assumed to be the liquidus temperature of the true invariant-point composition.

The effect of soda in the forms of the oxide and the compound $\mathrm{NC}_{8} \mathrm{~A}_{3}$ on this liquidus temperature is worthy of note, table 2 . Additions of 2 and 4 percent of $\mathrm{Na}_{2} \mathrm{O}$ raised the liquidus temperature above $1,400^{\circ}$, an increase of more than $50 \mathrm{deg}$. On the other hand, when soda was added in the form of $\mathrm{NC}_{8} \mathrm{~A}_{3}$ (10 to $20 \%$ ), the stable soda phase in clinker, the liquidus was lowered about $20 \mathrm{deg}$. to $1,330^{\circ}$. The addition of $\mathrm{Na}_{2} \mathrm{O}$ in the form of the oxide causes extensive changes in the potential compound composition of the mixture, through formation of $\mathrm{NC}_{8} \mathrm{~A}_{3}$. The effect of the addition of $\mathrm{Na}_{2} \mathrm{O}$ in the form of the oxide cannot therefore be readily interpreted. It is preferable to add 
$\mathrm{Na}_{2} \mathrm{O}$ in the form of $\mathrm{NC}_{8} \mathrm{~A}_{3}$, and this practice was followed in the remainder of the investigation.

The vertices of the small tetrahedron with additions of the soda phase were studied first, see table 3 and figure 2. It was found that those compositions obtained by adding $\mathrm{NC}_{8} \mathrm{~A}_{3}$ to vertices $V$ Q and $V_{4}$, representing higher concentrations of $\mathrm{C}_{5} \mathrm{~A}_{3}$ and $\mathrm{C}_{2} \mathrm{~F}$, respectively, melted at lower temperatures than the other two. Actually, compositions obtained by adding $\mathrm{NC}_{8} \mathrm{~A}_{3}$ to vertex $V 1$, higher $\mathrm{CaO}$ content, contained free $\mathrm{CaO}$ even when heated above $1,550^{\circ}$.

The centers of the faces of the tetrahedron were next studied. These compositions were prepared by mixing equal weight proportions of three vertex compositions. The center of the $V_{1}-V_{2}-V_{4}$ face had the lowest melting temperature.

When 10 to 30 percent of $\mathrm{NC}_{8} \mathrm{~A}_{3}$ was added to each of the $V 2, V 3$, and $V 4$ vertex compositions the liquidus temperature was increased except in the case of the 10-percent addition to vertex $V 2$, which reduced the liquidus temperature to $1,339^{\circ}$.

Having studied the boundaries of the small tetrahedron with and without additions of soda, planes within the tetrahedron were selected (fig. 2 .) To points within the tetrahedron representing quaternary compositions, $x$ percent of the soda phase was added, and $100-x$ percent of the amount of each of the four quaternary constituents making up this point was taken. In the plane studied, 10 percent of $\mathrm{NC}_{8} \mathrm{~A}_{3}$ was added, and the $\mathrm{C}_{2} \mathrm{~F}$ was held constant at 26 percent (quaternary composition). The remaining three components were then allowed to vary. The lowest melting composition in this plane, $10 \mathrm{~N} 26 \mathrm{~F} 5{ }^{6}$ listed in table 4 , was found to be all liquid at $1,318^{\circ}$. The iron phase appeared to be the primary phase. At only 2 deg. below this liquidus temperature, however, three solid phases were in equilibrium with liquid. This point, then, is on a bivariant surface in the quinary system and is probably near a univariant curve that extends to the invariant point. It is unusual that the first plane studied should be so close to the invariant point.

The next plane considered, 10 percent of $\mathrm{NC}_{8} \mathrm{~A}_{3}$ and 30 percent of $\mathrm{C}_{2} \mathrm{~F}$, contained no composition melting as low as the composition indicated by $10 \mathrm{~N} 26 \mathrm{~F} 5$ in the previous plane. The iron

\footnotetext{
6 For convenience and economy of space, the test number designation is used in place of the more complete form, for example, $10 \mathrm{~N}=10$ percent of $\mathrm{NC}_{8} \mathrm{~A}_{3}$, and $26 \mathrm{~F}=26$ percent of $\mathrm{C}_{2} \mathrm{~F}$, and $5=$ the fifth composition studied in this plane.
}

phase appeared in larger quantities. A few points in the $10 \mathrm{NC}_{8} \mathrm{~A}_{3}-34 \mathrm{C}_{2} \mathrm{~F}, 10 \mathrm{NC}_{8} \mathrm{~A}_{3}-38 \mathrm{C}_{2} \mathrm{~F}$, and $10 \mathrm{NC}_{8} \mathrm{~A}_{3}-42 \mathrm{C}_{2} \mathrm{~F}$ planes were studied to complete the series, but none of them melted as low as $1,318^{\circ}$. The plane $10 \mathrm{NC}_{8} \mathrm{~A}_{3}-22 \mathrm{C}_{2} \mathrm{~F}$ was also studied. Quenched charges in this plane contained the iron phase in small quantities but only as a secondary phase. This indicated that the invariant-point composition was at a higher value of $\mathrm{C}_{2} \mathrm{~F}$, that is, between 22 and 26 percent of $\mathrm{C}_{2} \mathrm{~F}$ (quaternary composition).

In the next series of planes the iron phase was held constant, and the soda phase varied from 5 to 30 percent (quinary composition). In the $5 \mathrm{NC}_{8} \mathrm{~A}_{3}-26 \mathrm{C}_{2} \mathrm{~F}$ plane, $\mathrm{NC}_{8} \mathrm{~A}_{3}$ did not appear as the primary phase, and the minimum liquidus temperature was again higher than that for the $10 \mathrm{NC}_{8} \mathrm{~A}_{3}-26 \mathrm{C}_{2} \mathrm{~F}$ plane.

The $20 \mathrm{NC}_{8} \mathrm{~A}_{3}-26 \mathrm{C}_{2} \mathrm{~F}$ plane was likewise at a higher liquidus temperature but contained $\mathrm{NC}_{8} \mathrm{~A}_{3}$ as the primary phase. Compositions in the $20 \mathrm{NC}_{8} \mathrm{~A}_{3}-30 \mathrm{C}_{2} \mathrm{~F}$ plane were studied. At this $\mathrm{C}_{2} \mathrm{~F}$ concentration (24\% in the quinary system) $F s s$ and $\mathrm{C}_{3} \mathrm{~A}$ appeared as the predominant phases. Compositions of minimum liquidus temperature in this plane were still further removed from the invariant point. Therefore, the invariant point would appear to contain less than 20 percent of $\mathrm{NC}_{8} \mathrm{~A}_{3}$ and near 26 percent $(23.4 \%$ in the quinary system) of $\mathrm{C}_{2} \mathrm{~F}$.

The 15 percent $\mathrm{NC}_{8} \mathrm{~A}_{3}-26$ percent $\mathrm{C}_{2} \mathrm{~F}$ plane was then studied. The temperature found for the point of lowest melting, $1,320^{\circ}$, was somewhat lower than that found in other planes, with the exception of the $10 \mathrm{NC}_{8} \mathrm{~A}_{3}-26 \mathrm{C}_{2} \mathrm{~F}$ plane. $F$ ss did not appear as a primary phase $(22.1 \%$ of $\mathrm{C}_{2} \mathrm{~F}$ in the quinary system). The primary phase in the compositions melting at lower temperatures was $\mathrm{NC}_{8} \mathrm{~A}_{3}$.

$\mathrm{A}$ few points were studied in the $15 \mathrm{NC}_{8} \mathrm{~A}_{3}-30 \mathrm{C}_{2} \mathrm{~F}$ plane. At this $\mathrm{C}_{2} \mathrm{~F}$ concentration $(25.5 \%$ in the quinary system) $F$ ss was the primary phase indicating an excess of $\mathrm{C}_{2} \mathrm{~F}$.

From the information gained in the study of these planes, additional compositions were chosen for study. These points are not shown in figure 2 but are given, together with petrographic observations of the quenched charges, in table 5 .

These data indicated that the invariant point should contain less $\mathrm{C}_{2} \mathrm{~F}$, more $\mathrm{NC}_{8} \mathrm{~A}_{3}$, and more $\mathrm{SiO}_{2}$ than point $10 \mathrm{~N} 26 \mathrm{~F} 5$ in the $10 \mathrm{NC}_{8} \mathrm{~A}_{3}-26 \mathrm{C}_{2} \mathrm{~F}$ 
TABLE 5. Quenching data on intermediate planes within the quinary system

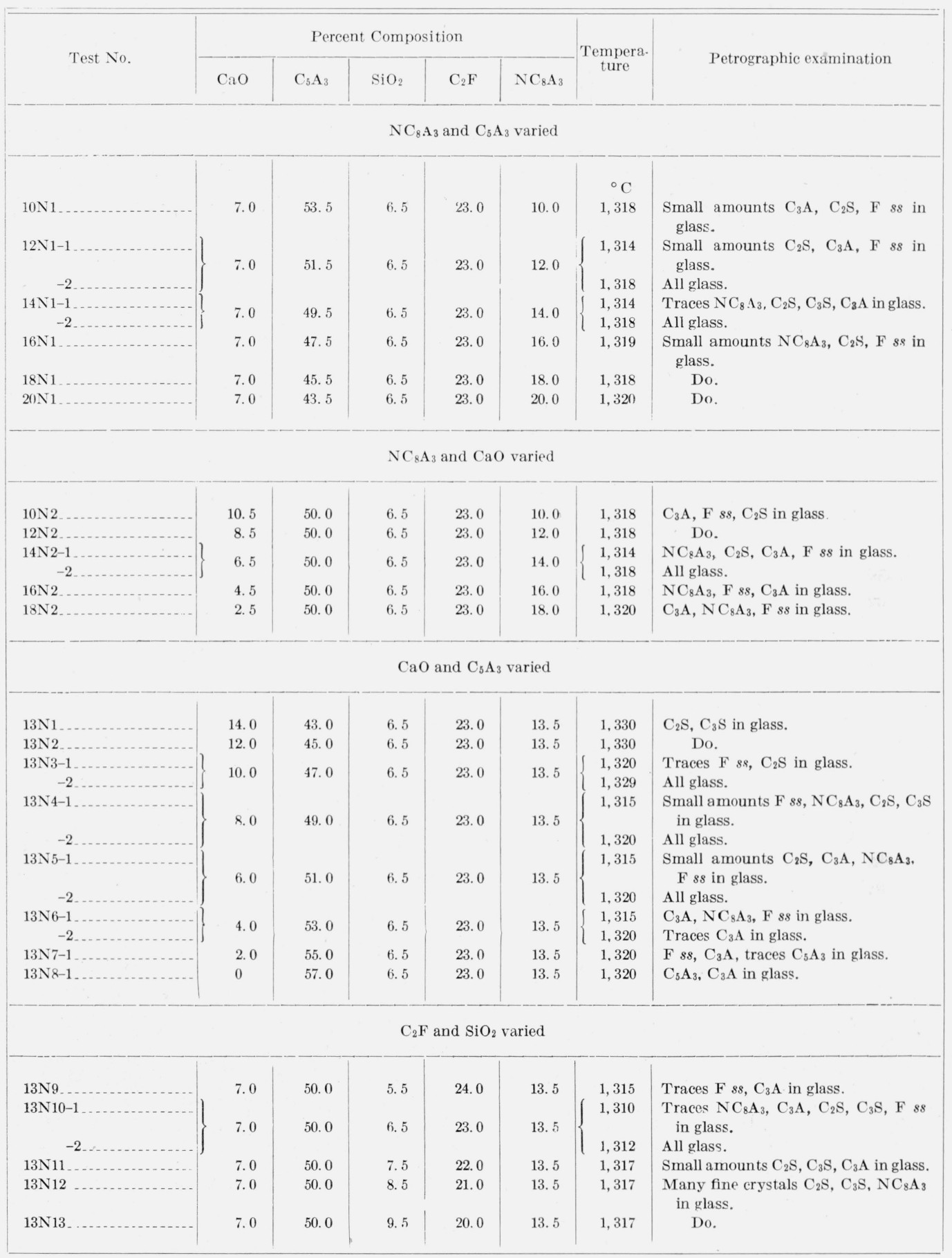


plane. Consequently, $\mathrm{NC}_{8} \mathrm{~A}_{3}$ was varied from 10 to 20 percent in two series of compositions. In both series $\mathrm{SiO}_{2}$ and $\mathrm{C}_{2} \mathrm{~F}$ were held constant at 6.5 and 23.0 percent, respectively (quinary composition). In the first series $\mathrm{CaO}$ was also held constant at 7.0 percent and $\mathrm{C}_{5} \mathrm{~A}_{3}$ and $\mathrm{NC}_{8} \mathrm{~A}_{3}$ varied, the sum of the latter two being constant. In the second series $\mathrm{C}_{5} \mathrm{~A}_{3}$ was held constant at 50.0 percent, and $\mathrm{CaO}$ and $\mathrm{NC}_{3} \mathrm{~A}_{3}$ varied with their sum constant.

Similar results were obtained for each series. The minimum temperature for complete melting $\left(1,316^{\circ}\right)$ appeared at slightly less $\mathrm{NC}_{8} \mathrm{~A}_{3}$ content than that for two 14-percent $\mathrm{NC}_{8} \mathrm{~A}_{3}$ compositions included in the preceding paragraph. This temperature is lower than that of any composition previously studied.

From these data it was deduced that the $\mathrm{NC}_{8} \mathrm{~A}_{3}$ value for the invariant point was near 13.5 percent. Because of this, another series of compositions (table 5) was prepared containing 13.5 $\mathrm{NC}_{8} \mathrm{~A}_{3}, 6.5 \mathrm{SiO}_{2}$, and 23.0 percent of $\mathrm{C}_{2} \mathrm{~F}$, and varying amounts of $\mathrm{C}_{5} \mathrm{~A}_{3}$ and $\mathrm{CaO}$. The lowest temperature for complete melting appeared between points containing $8.0 \mathrm{CaO}$ and 49.0 percent $\mathrm{C}_{5} \mathrm{~A}_{3}$ and $6.0 \mathrm{CaO}$ and 51.0 percent $\mathrm{C}_{5} \mathrm{~A}_{3}$. Slightly below the liquidus temperature four

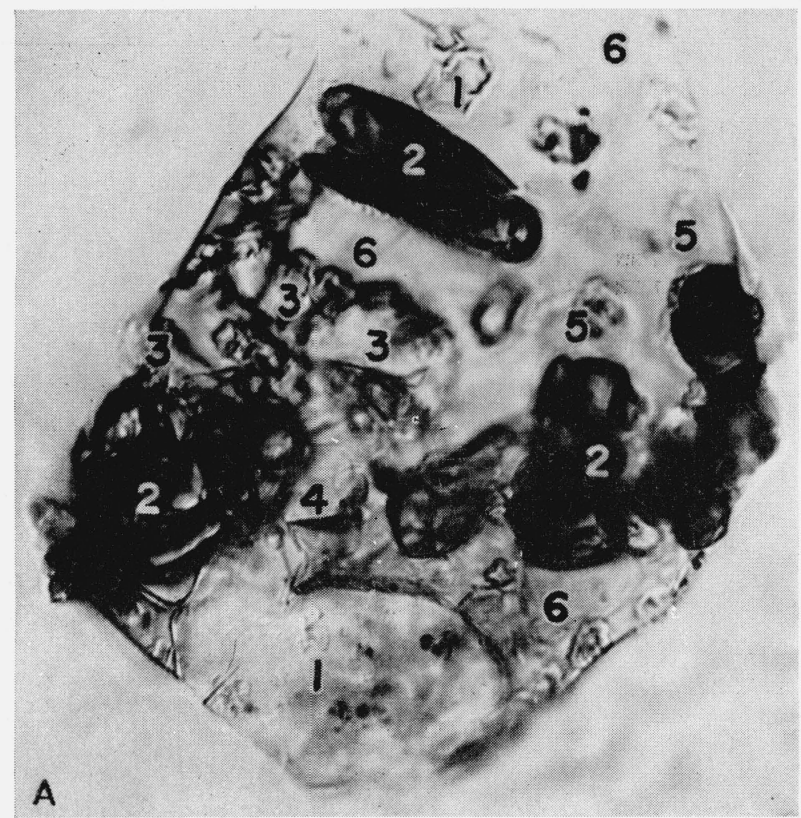

solid phases were in equilibrium with liquid indicating that the compositions were on univariant curves near the invariant point.

The final series was prepared to contain the composition midway between these points. $\mathrm{C}_{2} \mathrm{~F}$ and $\mathrm{SiO}_{2}$ were varied, and the other three components held constant. This intermediate composition, $13 \mathrm{~N} 10$, melted at $1,312^{\circ}$. At $1,310^{\circ}$ four and possibly five solid phases were observed in equilibrium with liquid. These crystalline phases in a glassy matrix are shown in figure 4 at a magnification of 470 diameters. The same field is shown both with and without crossed nicols.

The lower part of the field consists of a large, isotropic crystal of $\mathrm{C}_{3} \mathrm{~A}$ (phase 1, fig. 4, A) having a refractive index slightly below that of the mounting medium (1.715). It contains a few dark inclusions and extinguishes under crossed nicols (fig. 4, B). Near the upper part of the field a few small crystals of $\mathrm{C}_{3} \mathrm{~A}$ also appear. The iron-containing solid solution, Fss, phase 2, has much higher refractive indices than either the glassy matrix or the mounting medium and is in high relief. It is colored brownish-red to tan showing pleochroism and under crossed nicols gives highorder interference colors with red being predominant. Phase 3 is $\mathrm{C}_{2} \mathrm{~S}$, which appears near the left

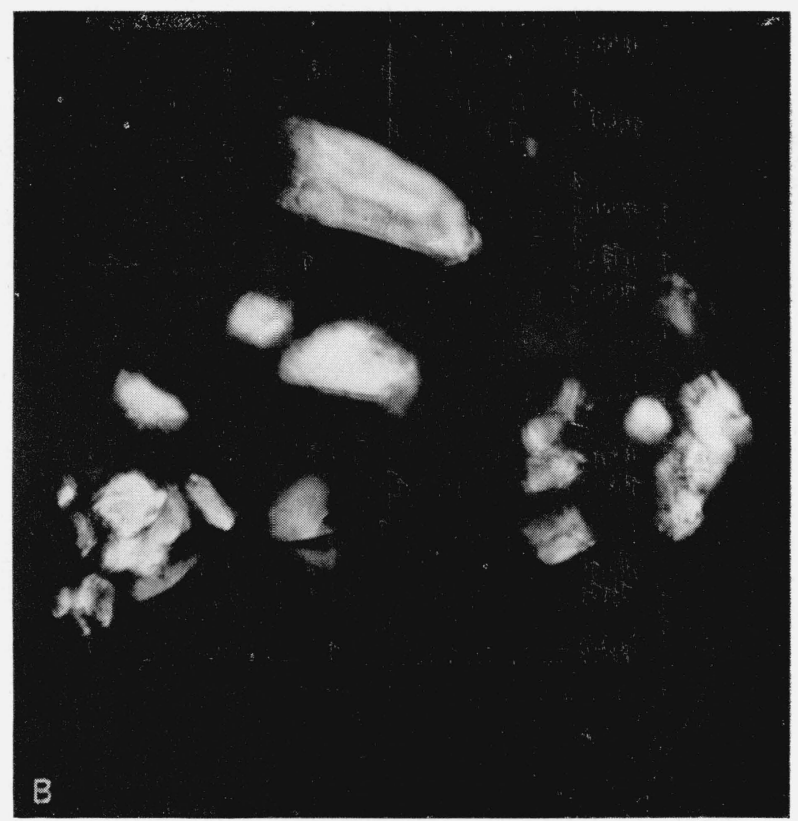

Figure 4. (A) Invariant poin composition quenched from $1,310^{\circ} C$ showing crystals of $\left.\mathrm{C}_{3} \mathrm{~A}(1), F s s(2), \mathrm{C}_{2} \mathrm{~S}(3), \mathrm{NC}_{8} \mathrm{~A}_{3}\right)$ (4), and $\mathrm{C}_{3} \mathrm{~S}$ (5) embedded in a glassy matrix (6), total magnification 470 diameters. (B) Same field under crossed nicols. 470 diameters. 
center of the field as clear crystals showing white to yellow birefringence. Phase 4 consists of small, transparent, flat grains of $\mathrm{NC}_{8} \mathrm{~A}_{3}$ having a comparatively lower degree of birefringence. A possible phase 5 , interpreted as $\mathrm{C}_{3} \mathrm{~S}$, occurs in very small grains having low birefringence (gray). Because of the similarity in optical properties of this phase and small particles of $\mathrm{NC}_{8} \mathrm{~A}_{3}$, identification was difficult. Phase 6 , the glassy matrix, is light tan in color (probably caused by the presence of iron) with a refractive index higher than that of the mounting medium.

Although color plays an important part in differentiating the above phases, other optical properties were also used for actual identification. It was not feasible to reproduce these micrographs in color. Also, in the relatively large specimen that was required for viewing the five crystalline phases it was difficult to focus all phases simultaneously.

From this and similar observations it appears that the invariant point for $\mathrm{NC}_{8} \mathrm{~A}_{3}, \mathrm{C}_{3} \mathrm{~A}, \mathrm{~F} s s$, $\mathrm{C}_{3} \mathrm{~S}, \mathrm{C}_{2} \mathrm{~S}$, and liquid is about $1,310^{\circ} \mathrm{C}$ and is near the composition point represented by $13 \mathrm{~N} 10$. The oxide composition of this point is about 1.0 percent- $\mathrm{Na}_{2} \mathrm{O}$, 48.0 percent-CaO, 31.0-percent $\mathrm{Al}_{2} \mathrm{O}_{3}$, 13.5 percent- $\mathrm{Fe}_{2} \mathrm{O}_{3}$, and 6.5-percent $\mathrm{SiO}_{2}$. Fivecomponent mixes in this quinary system approximating the composition of portland-cement clinker will crystallize completely at about $1,310^{\circ} \mathrm{C}$ upon slow cooling.

\section{Discussion}

In this investigation it was noted that additions of $\mathrm{Na}_{2} \mathrm{O}$ considerably lowered the temperature of appearance of first liquid. Certain low-melting mixes, for example, $10 \mathrm{~N} 26 \mathrm{~F} 5$, table 4 , showed some liquid formation when heated as low as $1,290^{\circ} \mathrm{C}$. Hansen [12] in studying a high-lime, low-alumina mix having the composition 2.2 $\mathrm{Na}_{2} \mathrm{O}, 65.7 \mathrm{CaO}, 6.4 \mathrm{Al}_{2} \mathrm{O}_{3}, 3.2 \mathrm{Fe}_{2} \mathrm{O}_{3}, 22.5$ percent $\mathrm{SiO}_{2}$ found that the first indications of melting occurred at $1,315^{\circ}$. Much higher temperatures are required for complete melting. In the present investigation, however, the invariant composition melts completely at about $1,310^{\circ}$.

The effect of $\mathrm{MgO}$ on the quinary invariant points is important to the chemistry of cement, as this component is present in the commercial product. Magnesia, together with the five components considered in this study, represents about 99 percent of the constitution of clinker. Since there has been no evidence of new phases formed when $\mathrm{MgO}$ is present [11], it is probable that only a lowering of the melting temperature results. Swayze [2] found that about 5 percent of $\mathrm{MgO}$ could be dissolved in the liquids studied in the system $\mathrm{CaO}-\mathrm{C}_{5} \mathrm{~A}_{3}-\mathrm{C}_{2} \mathrm{~F}-\mathrm{C}_{2} \mathrm{~S}$ as a result of which the temperatures at invariant points were lowered by about $35 \mathrm{deg}$. It may be permissible on the same basis to predict that $\mathrm{MgO}$ may lower the quinary invariant temperature from $1,310^{\circ}$, found in this investigation, to about $1,275^{\circ}$. Hansen [12] found that melting started at about this temperature $\left(1,280^{\circ}\right)$ when a mixture of these six components was burned.

The results also indicate that a closer computation of the actual percentage of liquid formed may be made when mixes containing $\mathrm{Na}_{2} \mathrm{O}$ are burned. Thus, instead of adding the percentage of $\mathrm{Na}_{2} \mathrm{O}$ present to the calculated percentage of liquid as has been suggested [13], one must also consider the effect of formation of $\mathrm{NC}_{8} \mathrm{~A}_{3}$ on the relative proportions of $\mathrm{CaO}$ and $\mathrm{Al}_{2} \mathrm{O}_{3}$.

The observations made in this study have established the stable existence of the soda compound $\mathrm{NC}_{8} \mathrm{~A}_{3}$ in the presence of the principal components of portland cement clinker.

Under certain conditions $\mathrm{Na}_{2} \mathrm{O}$ may react with other components, producing new phases. The data also indicate that a closer approximation of the glass composition in rapidly cooled clinker can be made.

The data obtained for the quinary system represent equilibrium conditions, whereas in the commercial clinkering operation this is not the case and must be considered when applying these data. Application is further limited, since the effects of the small amounts of minor constituents such as $\mathrm{Mn}_{2} \mathrm{O}_{3}, \mathrm{TiO}_{2}, \mathrm{Li}_{2} \mathrm{O}$, and others on the phaseequilibrium relations of the system are not known. More information on the quinary system itself will be necessary in order that wider application to the problems of cement manufacture may be made. 


\section{References}

[1] F. M. Lea and T. W. Parker, Phil. Trans. Royal Soc. [A], 234, No. 731, 1 (1934).

[2] M. A. Swayze, Am. J. Sci. 244, 1; 65 (1946).

[3] K. T. Greene and R. H. Bogue, J. Research NBS 36, 187 (1946) RP1699; PCAF Paper 47.

[4] W. R. Eubank and R. H. Bogue, J. Research NBS 40, 225 (1948) RP1867; PCAF Paper 50.

[5] R. H. Bogue, The chemistry of portland cement (Reinhold Pub. Co., New York, N. Y., 1947).

[6] K. T. Greene and W. R. Morgan, J. Am. Ceram. Soc. 24, 111 (1941).

[7] W. R. Eubank, Precision thermostat for high temperatures (publication pending).
[8] L. A. Dahl, Parametric equations in the treatment of multi-component systems, J. Phys. Colloid Chem. (publication pending).

[9] L. A. Dahl, J. Phys. Colloid Chem. 52, 698 (1948); PCAF Paper 51.

[10] L. A. Dahl, J. Chem. Education 26, 411 (1949); PCAF Paper 52.

[11] H. F. MeMurdie and H. Insley, J. Research NBS 16, 467 (1936) RP884.

[12] W. C. Hansen, B. S. J. Research 2, 55 (1930) RP132; PCAF Paper 22.

[13] F. M. Lea and T. W. Parker, Build. Res. Tech. Pap. No. 16 (1935).

Washington, November 8, 1948. 